Brazilian Journal

of Chemical

ISSN 0104-6632

Printed in Brazil

Engineering

www.scielo.br/bjce

Vol. 35, No. 03, pp. 901-908, July - September, 2018

dx.doi.org/10.1590/0104-6632.20180353s20170265

\title{
CAN VINASSE BE USED AS CARBON SOURCE FOR POLY(3-HYDROXYBUTYRATE) PRODUCTION BY Cupriavidus necator DSM 545?
}

\author{
Kellen Zanfonato ${ }^{1}$, Mélodi Schmidt ${ }^{1}$, Luci Kelin Quines ${ }^{1}$, Cláudia Santos Gai ${ }^{1}$, \\ Willibaldo Schmidell ${ }^{1}$ and Gláucia Maria Falcão de Aragão ${ }^{1, *}$ \\ ${ }^{1}$ Department of Chemical and Food Engineering, Federal University of Santa \\ Catarina, UFSC, PO Box 476, Florianópolis, SC 88040-900, Brazil
}

Phone +554837215232

(Submitted: May 19, 2017; Revised: August 11, 2017; Accepted: October 19, 2017)

\begin{abstract}
Vinasse is the main liquid waste of the ethanol industry and its valorization by a bioprocess as a substrate for production of a value-added product contributes to the ethanol process. This work aimed to study the possibility to use vinasse for poly(3-hydroxybutyrate) (PHB) production by Cupriavidus necator. The growth of $C$. necator was evaluated using different vinasse concentrations and no inhibitory effect was observed. Cultivations in a bioreactor were carried out with pure vinasse, vinasse with nitrogen and vinasse with nitrogen and mineral salts. The best values of total biomass $\left(5.1\right.$ g. $\left.\mathrm{L}^{-1}\right)$ and PHB (26\% of total biomass) were obtained in the cultivation with nitrogen and salts added. The results indicated that vinasse could be used for PHB production. However, vinasse should be used in association with another substrate, aiming to improve the production. This is the first report on vinasse valorization for PHB production by C. necator.
\end{abstract}

Keywords: Cupriavidus necator; Polyhydroxyalkanoates; Vinasse.

\section{INTRODUCTION}

The widespread use of fuel-based plastics causes several environmental problems and one of the solutions found to replace them has been the development of biodegradable plastics (Reddy et al., 2003). Among different biodegradable polymers are the polyesters synthesized by microorganisms, recombinant plants and cyanobacteria, called polyhydroxyalkanoates (PHA). PHA can be produced from a wide range of substrates such as renewable sources, organic acids, fossil resources and wastes (Dietrich et al., 2017). PHB is the most important member of PHA, since it has physical properties comparable to synthetic polymers (Anderson and Dawes, 1990).
Several microorganisms are able to produce PHB (Anjum et al., 2016). Among these, the bacteria $C$. necator is extensively studied due to its high capacity of biopolymer accumulation (up to $80 \%$ ) with high cell yield and the ability to use different carbon sources. The microbial production of PHA by $C$. necator is mainly based on the limitation of a nutritional element in the presence of an abundant source of carbon (Madison and Huisman, 1999).

Several studies have been carried out on developing efficient PHA production processes, but its production costs are still high (estimated to be 3-4 times higher) when compared to conventional plastics (Kourmentza et al., 2017). Raw material is one of the major reasons for high cost and the carbon source for

*Corresponding author. E-mail address: glaucia.aragao@ufsc.br 
PHB production accounts for up to $45 \%$ of the total biopolymer production costs (Posada et al., 2011).

Sugarcane vinasse represents the main co-product from ethanol production. About 10 to $16 \mathrm{~L}$ of vinasse are obtained per each liter of ethanol produced (Salomon and Silva Lora, 2009). Brazil is one of the world's leading ethanol producer and exporter. Due to increasing fuel demands, ethanol production has increased in recent years and consequently the vinasse production. The Brazilian Department of Agriculture, Livestock and Supply reported that, for the year 2030, ethanol production could reach 67 million cubic meters. If estimates are reached, more than 850 million cubic meters of vinasse will be available. Usually, the destination of vinasse is on the sugarcane fields and this practice is known as fertirrigation (Cavalett et al., 2012), but it can result in negative environmental impacts on soil and groundwater quality (Braga et al., 2017; Carvalho et al., 2017).

The main organic compounds present in sugarcane vinasse are glycerol, lactic acid, ethanol and acetic acid (Parnaudeau et al., 2008). However, until recently, the literature presents few examples of vinasse utilization as a substrate for the production of value-added products with potential industrial uses, such as PHA (Bhattacharyya et al., 2012; Pramanik et al., 2012).

Thus, the aim of this study was to verify the applicability of vinasse concentrations on $C$. necator growth as a low-cost carbon source. We also evaluated biomass growth and PHB production by $C$. necator using vinasse with and without salts addition.

\section{MATERIALS AND METHODS}

\section{Microorganism}

The microorganism used in this work was Cupriavidus necator DSM 545 (Deutsche Sammlungvon Mikroorganismen und Zellkulturen, Braunschweig, Germany). C. necator cells were stored at $-80{ }^{\circ} \mathrm{C}$ in NB medium (Nutrient Broth - Difco(tm): meat peptone 5 g. $\mathrm{L}^{-1}$, meat extract 3 g. $\mathrm{L}^{-1}$ ) and glycerol $(1: 1)$.

\section{Pretreated vinasse preparation}

The vinasse used in this study was collected at Usina Iracema, located in Iracemápolis, São Paulo, Brazil. Vinasse was stored at $-20{ }^{\circ} \mathrm{C}$ until its utilization. The $\mathrm{pH}$ was adjusted to 7.0 with a $\mathrm{NaOH}$ solution $\left(2.5 \mathrm{~mol}^{\mathrm{L}} \mathrm{L}^{-1}\right)$ and sterilized by filtration using a cross-flow type polypropylene membrane (Mycrodin
Nadirmodel MD020 CP 2 N, Frings Brasil) with a pore diameter of $0.2 \mu \mathrm{m}$ and filtration area of $0.1 \mathrm{~m}^{2}$. All the experiments presented in this study were performed on pretreated vinasse.

\section{Vinasse characterization}

The composition characterization was carried out on pretreated vinasse. The concentration of total chlorides was determined with an ion-selective electrode using the protocol described by ASTM D512 (Orion 920 A; combined electrode Cole Parmer 27504-D8). Sulphates were analyzed using the protocol described by ASTM D516 (Analytical Balance AND HR 200). Ca, Fe, Mn, $\mathrm{Mg}, \mathrm{Cu}$ and $\mathrm{Zn}$ were analyzed by atomic absorption (Perkin Elmer - PinAAcle 900T0); K was analyzed by atomic emission (Perkin Elmer - PinAAcle 900T0) and $\mathrm{Na}$ by flame photometry (Cole Parmer 265500); the samples were prepared using the protocol described by ASTM D 1971/16 Practice B.

The concentrations of nitrogen, total reducing sugars (TRS) and glycerol were determined as described in the following sections.

\section{Culture medium and cultivation conditions}

\section{Pre-culture}

C. necator cells from $-80^{\circ} \mathrm{C}$ stocks were transferred to $500 \mathrm{~mL}$ shake flasks, containing $150 \mathrm{~mL}$ of $\mathrm{NB}$, and incubated at $35^{\circ} \mathrm{C}$ at $150 \mathrm{rpm}$ for $18 \mathrm{~h}$.

\section{C. necator growth on vinasse}

To investigate if vinasse inhibited C. necator growth, different vinasse concentrations were evaluated: pure vinasse; $25 \%$ vinasse ( v. $^{-1}$ ) on mineral medium (MM); $50 \%$ vinasse $\left({\left.\mathrm{v} . \mathrm{v}^{-1}\right)}^{-1}\right.$ on $\mathrm{MM} ; 100 \%$ vinasse $\left(\mathrm{v} . \mathrm{v}^{-1}\right)$ plus $\mathrm{MM}$ components. A cultivation using glucose $(20 \mathrm{~g} . \mathrm{L}$ $\left.{ }^{1}\right)$ as carbon source was used as a control.

The mineral medium used in this study was previously described (Aragão et al., 1996), containing (in g. $\mathrm{L}^{-1}$ ): $\mathrm{KH}_{2} \mathrm{PO}_{4}$ 1.0, ammonium citrate and iron (III) $0.06, \mathrm{CaCl}_{2} .2 \mathrm{H}_{2} \mathrm{O} \quad 0.01, \quad \mathrm{MgSO}_{4} .7 \mathrm{H}_{2} \mathrm{O} \quad 0.5$, nitrilotriacetic acid 0.19 , urea 2.27 and $1 \mathrm{~mL}$ trace elements $\mathrm{L}^{-1}$. The trace elements solution contained (in g. $\left.\mathrm{L}^{-1}\right) \mathrm{H}_{3} \mathrm{BO}_{3} 0.3, \mathrm{CoCl}_{2} \cdot 6 \mathrm{H}_{2} \mathrm{O} 0.2, \mathrm{ZnSO}_{4} .7 \mathrm{H}_{2} \mathrm{O} 0.1$, $\mathrm{MnCl}_{2} \cdot 4 \mathrm{H}_{2} \mathrm{O} 0.03, \mathrm{Na}_{2} \mathrm{MoO}_{4} \cdot 2 \mathrm{H}_{2} \mathrm{O} 0.03, \mathrm{NiCl}_{2} \cdot 6 \mathrm{H}_{2} \mathrm{O}$ 0.02 and $\mathrm{CuSO}_{4} .5 \mathrm{H}_{2} \mathrm{O} 0.01$.

Forty milliliters of pre-culture (prepared as mentioned) were transferred to $1000 \mathrm{~mL}$ shake flasks, containing $360 \mathrm{~mL}$ of each different cultivation condition and incubated at $35^{\circ} \mathrm{C}$ at $150 \mathrm{rpm}$. 


\section{$P H B$ production by $C$. necator on vinasse}

Three batch experiments were performed in a $5 \mathrm{~L}$ bioreactor (BIOFLO III, New Brunswick Scientific), with a working volume of $4 \mathrm{~L}$. One performed on pure vinasse, one using vinasse and nitrogen source and other using vinasse, nitrogen source in MM. In these experiments, the temperature was maintained at 35 ${ }^{\circ} \mathrm{C}$ and the $\mathrm{pH}$ was maintained at 7.0 by adding base $\left(\mathrm{NaOH} 2.5\right.$ mol.L $\left.\mathrm{L}^{-1}\right)$ or acid $\left(\mathrm{HCl} 2.5\right.$ mol.L $\left.\mathrm{L}^{-1}\right)$. The impeller speed (from 450 to $950 \mathrm{rpm}$ ) and specific air flow rate (from 0.1 to $1.0 \mathrm{vvm}$ ) were adjusted during the cultivation aiming to keep the concentration of dissolved oxygen not less than $40 \%$ (relative saturation with atmospheric air). When necessary, anti-foaming solution (polypropylene glycol) was added to avoid foam over production in the bioreactor.

A two-step seed procedure was cultivated in shake flasks prior to inoculum preparation. The first one was on NB, and the second seed culture was on vinasse plus MM components. Seed cultures were incubated for 18 $\mathrm{h}$ and $8 \mathrm{~h}$ respectively, at $150 \mathrm{rpm}, 35^{\circ} \mathrm{C}$ and employed as an inoculum for the bioreactor cultivations.

\section{Analytical methods}

Cell density was determined indirectly by optical density at $600 \mathrm{~nm}\left(\mathrm{OD}_{600 \mathrm{~nm}}\right)$ and directly by gravimetric analysis. The carbon source concentration was determined by the 3.5-dinitrosalicylic (DNS) acid method (Miller, 1959). Nitrogen concentration was determined by the enzymatic colorimetric method (kit Urea-ES -Gold Analisa Diagnóstica Ltda). The PHB concentration was determined by High Performance Liquid Chromatography (HPLC) (LC 2000Plus Series; Jasco) equipped with a refractive index detector (RI 2031Plus; Jasco) using an Aminex HPX-87H column (Bio-Rad Laboratories), according to the method described by Karr et al. (1983), with modifications.

The residual biomass concentration (Xr) was obtained from the difference between the fitted values of the total biomass (Xt) and PHB. The dissolved oxygen concentration was measured with a galvanic electrode (Mettler-Toledo GmbH, Switzerland). Glycerol concentration was determined by HPLC equipped with a refractive index detector (RI 2031Plus; Jasco) using an Aminex HPX-87H column (Bio-Rad Laboratories).

\section{Kinetic analysis}

The kinetic analysis of the results was performed by fitting a polynomial equation through the macro
Lissage (from the INSA - Toulouse, France) for Microsoft Office Excel 2007. The maximum specific growth rate $\left(\mu_{\max }\right)$ was calculated from the linear fit of $\ln (\mathrm{Xr})$ versus time for data of the exponential growth phase.

\section{RESULTS AND DISCUSSION}

The vinasse composition used in this work is shown in Table 1. Some parameters like $\mathrm{pH}, \mathrm{Fe}, \mathrm{Cu}$ are according to the average found in the literature (España-Gamboa et al., 2012). Glycerol (4.5 g.L-1) and fructose (3.3 g. $\left.\mathrm{L}^{-1}\right)$ were the main substrates available in vinasse as carbon source for $C$. necator. This microorganism can also consume organic acids such as lactate, acetate, propionate and butyrate also generally present in vinasse (Parnaudeau et al., 2008).

The study of $C$. necator growth kinetics using different vinasse concentrations was evaluated to verify a potential vinasse inhibition effect on $C$. necator growth.

Table 1. Chemical composition of the vinasse used in this work.

\begin{tabular}{|c|c|}
\hline Parameter & This work \\
\hline $\mathrm{pH}$ & 4.4 \\
\hline Nitrogen (g. $\left.\mathrm{L}^{-1}\right)$ & 0.06 \\
\hline Fructose $\left(\mathrm{g} \cdot \mathrm{L}^{-1}\right)$ & 3.3 \\
\hline Glycerol (g.L $\left.{ }^{-1}\right)$ & 4.5 \\
\hline Sucrose $\left(\mathrm{g} \cdot \mathrm{L}^{-1}\right)$ & 7.2 \\
\hline Chlorides (\%) & 0.158 \\
\hline Sulphates (\%) & 0.096 \\
\hline $\mathrm{Ca}\left(\mathrm{mg} \cdot \mathrm{L}^{-1}\right)$ & 578 \\
\hline $\mathrm{Fe}\left(\mathrm{mg} \cdot \mathrm{L}^{-1}\right)$ & 23.2 \\
\hline $\operatorname{Mn}\left(m g . L^{-1}\right)$ & 3.21 \\
\hline $\operatorname{Mg}\left(\mathrm{mg} \cdot \mathrm{L}^{-1}\right)$ & 138.8 \\
\hline $\mathrm{Cu}\left(\mathrm{mg} \cdot \mathrm{L}^{-1}\right)$ & 0.66 \\
\hline $\mathrm{Zn}\left(\mathrm{mg} \cdot \mathrm{L}^{-1}\right)$ & 0.43 \\
\hline $\mathrm{K}\left(\mathrm{g} \cdot \mathrm{L}^{-1}\right)$ & 1.2 \\
\hline $\mathrm{Na}\left(\mathrm{mg} \cdot \mathrm{L}^{-1}\right)$ & 75 \\
\hline COD - Chemical Oxygen Demand (mg.L-1-1) & 22700 \\
\hline
\end{tabular}

Figure 1 shows the time course of $\mathrm{OD}_{600 \mathrm{~nm}}$ for $C$. necator cultivated on pure vinasse; $25 \%$ vinasse on $\mathrm{MM} ; 50 \%$ vinasse on $\mathrm{MM} ; 100 \%$ vinasse plus $\mathrm{MM}$ components and on glucose on MM as control.

The results showed that pretreated vinasse allowed C. necator growth even on pure vinasse. There are some contradictions regarding the inhibitory effect of vinasse compounds on microbial growth. Some reports state that the presence of compounds such as phenolics can be toxic and/or inhibit the growth of microorganisms (Martín Santos et al., 2003; Yu and 


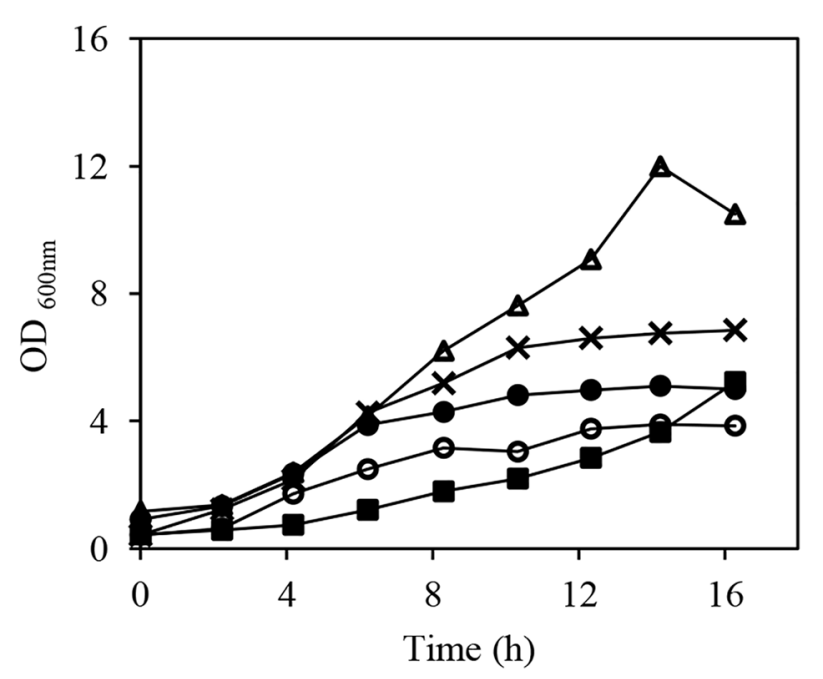

Figure 1. Time courses of optical density $\left(\mathrm{OD}_{600 \mathrm{~nm}}\right)$ on pure vinasse $(\bullet)$; glucose $\left(20\right.$ g. $\left.\mathrm{L}^{-1}\right)$ in MM (ロ); $25 \%$ vinasse in MM (०); $50 \%$ vinasse in $\mathrm{MM}(\mathrm{x}) ; 100 \%$ vinasse in $\mathrm{MM}(\Delta)$.

Stahl, 2008). On the other hand, according to Silva et al. (2011), one of the advantages of using vinasse in biotechnological processes is that it is free of fermentation inhibitors. As shown, the current study did not observe inhibitory effects.

During the experiments on MM containing vinasse (25; 50 and $100 \%$ ), the higher its concentration, the higher was the final OD, representing indirectly the biomass concentration.

Glucose was chosen as control substrate, since it is a very widespread carbon source for this microorganism. According to Figure 1, the bacteria grew faster on vinasse than on glucose. The presence of vinasse in the culture medium increased the values of $\mu_{\max }$ from $0.26 \mathrm{~h}^{-1}$ (pure vinasse) compared to the value observed on glucose $\left(0.16 \mathrm{~h}^{-1}\right)$. This data is in agreement with those reported in the literature for $C$. necator growing on glucose (Mozumber et al., 2014).

Vinasse utilization influenced positively bacterial growth; this can probably be attributed to the presence of organic acids in this co-product. Grousseau et al. (2013) used organic acids as carbon source for $C$. necator DSM 545, and also observed higher $\mu_{\max }$ values when compared with glucose.

To compare the cellular growth and $\mathrm{PHB}$ production on vinasse, vinasse with nitrogen source and vinasse in $\mathrm{MM}$ (with nitrogen), three bioreactor experiments were performed. The results of $\mathrm{Xt}, \mathrm{PHB}$ and $\mathrm{Xr}$ for the cultivations are presented in Fig. 2A, $2 \mathrm{~B}$ and $2 \mathrm{C}$, respectively.

Figure 2A shows that the highest total biomass (Xt) using pure vinasse as substrate was 1.6 g. $\mathrm{L}^{-1}$ after 16 $\mathrm{h}$ of cultivation, with a $\mu_{\text {máx }}$ of $0.26 \mathrm{~h}^{-1}$. The natural
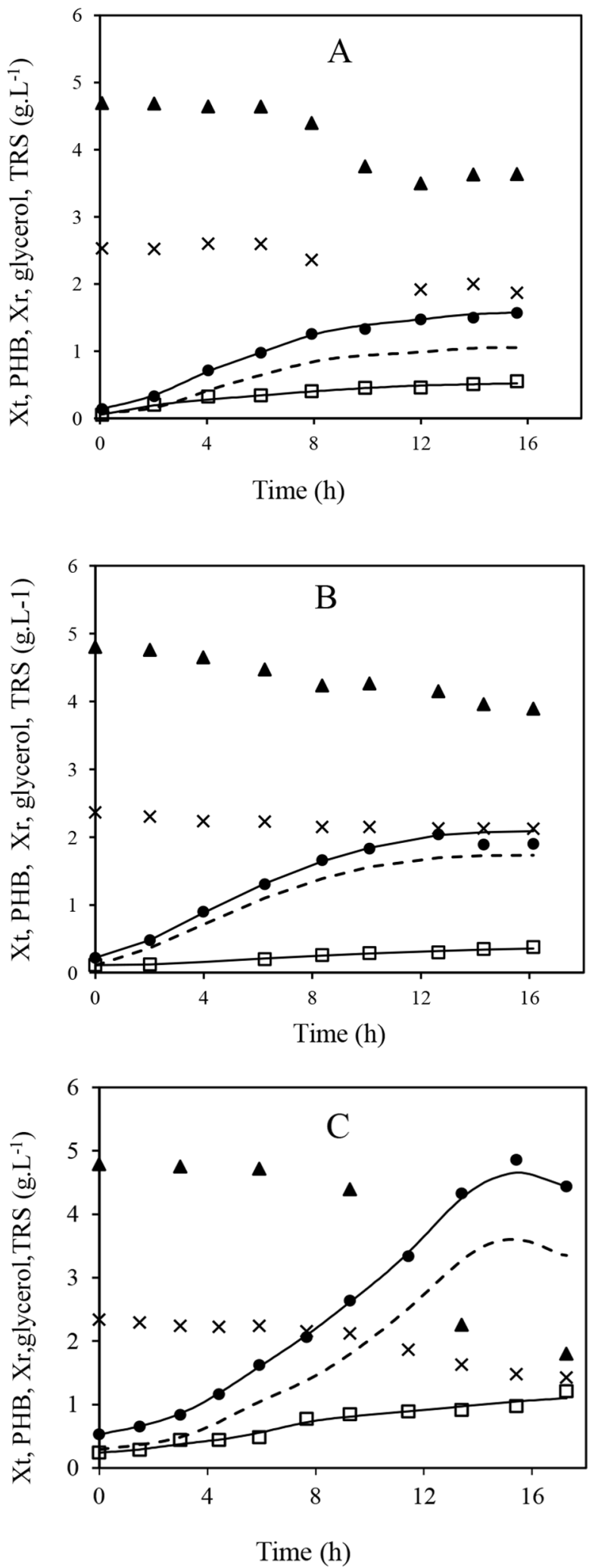

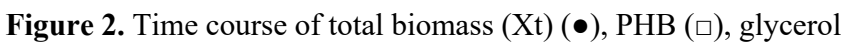
$(\boldsymbol{\Delta})$ and total reducing sugars (TRS) (x), on vinasse (A), vinasse with nitrogen (B) and vinasse in $\mathrm{MM}(\mathrm{C})$. Continuous lines represent the Lissage fit to the experimental data. Dashed line represents the residual biomass (Xr) (---), i.e., the difference between the Xt and PHB fits. 
nitrogen concentration present in vinasse, when this culture started, was approximately 0.06 g.L. L $^{-1}$. This concentration indicated nitrogen limitation, according to Ienczak et al. (2011) since the beginning of the culture and allowed PHB accumulation during all the course of the culture even with low carbon available, achieving a concentration around $35 \%$. Since this cultivation (Fig. 2A) was conducted on pure vinasse (nitrogen concentration of 0.06 g.L ${ }^{-1}$ ) and if we consider a yield factor from nitrogen of $8 \mathrm{~g}^{\mathrm{g}} \mathrm{g}^{-1}$ (Ienczak et al., 2011), this would give 0.48 g.L $\mathrm{L}^{-1}$ of $\mathrm{Xr}$, instead of $1 \mathrm{~g} . \mathrm{L}^{-1}$, as observed. This difference may be due to residual nitrogen from the pre-culture.

This observation suggested another cultivation using vinasse and a nitrogen source, aiming to compare and to verify if the presence of nitrogen could have positively influenced the results found in vinasse. The results obtained are presented in Figure 2B. With the addition of a nitrogen source, the final total biomass increased from 1.6 to 2.3 g.L. $\mathrm{L}^{-1}$, indicating that the amount of nitrogen present in the vinasse alone was not sufficient for the growth of C. necator DSM 545 in the bioreactor. The final PHB concentration was about $15 \%$; the small accumulation was expected, given the non-nutritional limitation, which is necessary for the bacteria biopolymer production phase (Lynd, 1996).

In the cultivation (Figure 2C) using vinasse with the addition of MM salts and nitrogen, $\mu_{\text {máx }}$ was $0.21 \mathrm{~h}^{-1}$ and the total biomass achieved 5 g.L $\mathrm{L}^{-1}$, representing more than three times the amount of biomass present in the first bioreactor. The salts and nitrogen addition improved the assimilation of carbon sources present in vinasse. More studies are needed to better understand residual carbon source assimilation, since microbial growth seems to stop when some carbon is still available ( 2 g.L $\mathrm{L}^{-1}$ of glycerol and 1.5 g.L $\mathrm{L}^{-1}$ of TRS). PHB content in this condition was about $26 \%$. The accumulation may be explained by the absence of nitrogen limitation and no excess of carbon (required for PHB production).

Myshkina et al. (2008), aiming to produce PHB using Azotobacter charoococcum from vinasse

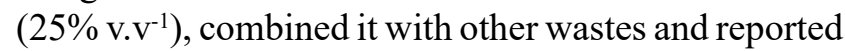
an accumulation of $73 \%$ of biopolymer, but the authors also used sucrose in the cultivation medium. This fact indicates that vinasse may be combined with other carbon sources for high PHB production.

The positive effect of vinasse on the $C$. necator specific growth rate, observed in the present study, shows the viability of its use during the growth phase, allowing overall process productivity improvement.

\section{CONCLUSIONS}

C. necator growth was not inhibited even under high vinasse concentrations and the addition of salts to vinasse improved its growth. This microorganism was able to produce PHB under the tested conditions. However, the bacterial growth and the PHB production seem to be limited by the low carbon concentration present in vinasse. In order to increase the biomass concentration and PHA productivity from vinasse, another carbon source could be used combined with vinasse.

\section{ACKNOWLEDGMENTS}

The authors thank the CNPq and CAPES (Brazil) for financial support.

\section{NOMENCLATURE}

$\mathrm{Ca} \quad$ Calcium concentration (mg. $\left.\mathrm{L}^{-1}\right)$

COD Chemical Oxygen Demand (mg. $\left.\mathrm{L}^{-1}\right)$

$\mathrm{Cu} \quad$ Copper concentration (mg. $\left.\mathrm{L}^{-1}\right)$

DNS Dinitrosalicylic acid

$\mathrm{Fe} \quad$ Iron concentration $\left(\mathrm{mg} . \mathrm{L}^{-1}\right)$

HPLC High performance liquid chromatography

K Potassium concentration (g. $\left.\mathrm{L}^{-1}\right)$

$\mathrm{Mg} \quad$ Magnesium concentration (mg. $\left.\mathrm{L}^{-1}\right)$

MM Mineral medium

Mn Manganese concentration (mg. $\mathrm{L}^{-1}$ )

$\mathrm{Na} \quad$ Sodium concentration (mg. $\left.\mathrm{L}^{-1}\right)$

NB Nutrient broth

$\mathrm{OD}_{600 \mathrm{~nm}}$ Optical density at $600 \mathrm{~nm}$

PHA Polyhydroxyalkanoates

PHB Poly(3-hydroxybutyrate) (g.L L $\left.^{-1}\right)$

vvm Volume of air per volume of medium per minute

$\mathrm{Xr} \quad$ Residual biomass (g.L $\left.\mathrm{L}^{-1}\right)$

$\mathrm{Xt} \quad$ Total biomass $\left(\mathrm{g} . \mathrm{L}^{-1}\right)$

TRS Total reducing sugars (g.L $\left.\mathrm{L}^{-1}\right)$

Zn Zinc concentration (mg. $\left.\mathrm{L}^{-1}\right)$

$\mu_{\max } \quad$ Maximum specific growth rate $\left(\mathrm{h}^{-1}\right)$

\section{REFERENCES}

Anderson, A. J. and Dawes, E. A., Occurrence, metabolism, metabolic role, and industrial uses of bacterial Polyhydroxyalkanoates. Microbiological reviews, 54, No 4, 450-472 (1990).

Anjum, A., Zuber, M., Zia, K. M., Noreen, A., Anjum, M. N., Tabasum, S., Microbial production of polyhydroxyalkanoates (PHAs) and its copolymers: A review of recent advancements. International 
Journal of Biological Macromolecules, 89, 161174 (2016).

Aragão, G. M. F., Lindley, N. D., Uribelarrea, J. L., Pareilleux, A., Maintaining a controlled residual growth capacity increases the production of polyhydroxyalkanoate copolymers by Alcaligenes eutrophus. Biotechnology Letters, 18, 937-942 (1996).

Bhattacharyya,A., Pramanik,A., Maji, S. K., Haldar, S., Mukhopadhyay, U. K., Mukherjee, J., Utilization of vinasse for production of poly-3-(hydroxybutyrateco-hydroxyvalerate) by Haloferax mediterranei. AMB Express, 2, 34 (2012).

Braga, L. P. P., Alves, R. F., Dellias, M. T. F., Navarrete, A. A., Basso, T. O., Tsai, S. M., Vinasse fertirrigation alters soil resistome dynamics: an analysis based on metagenomic profiles. BioData Mining, 10, 17 (2017).

Carvalho, J. L. N., Nogueirol, R. C., Menandro, L. M. S., Bordonal, R. O., Borges, C. D., Cantarella, H., Franco, H. C. J., Agronomic and environmental implications of sugarcane straw removal: a major review. GCB Bioenergy, 9, 1181-1195 (2017).

Cavalett, O., Junqueira, T.L., Dias, M.O.S., Jesus, C.D.F., Mantelatto, P.E., Cunha, M.P., Franco, H.C.J., Cardoso, T.F., Filho, R.M., Rossell, C.E.V., Bonomi, A., Environmental and economic assessment of sugarcane first generation biorefineries in Brazil. Clean Technologies and Environmental Policy, 14, 399-410 (2012).

Dietrich, K., Dumont, M. J., Del Rio, L. F. Orsat, V., Producing PHAs in the bioeconomy - Towards a sustainable bioplastic. Sustainable Production and Consumption, 9, 58-70 (2017).

Espana-Gamboa, E., Mijangos-Cortes, J., Barahona-Perez, L., Dominguez-Maldonado, J., Hernandez-Zarate, G., Alzate-Gaviria, L., Vinasses: characterization and treatments, Waste Management \& Research, 29, No 12, 1235-1250 (2011).

Grousseau, E., Blanchet, E., Déléris, S., Albuquerque, M. G. E., Paul, E., Uribelarrea, J. L., Impact of sustaining a controlled residual growth on polyhydroxybutyrate yield and production kinetics in Cupriavidus necator, Bioresource Technology, 148, 30-38 (2013).

Ienczak, J. L., Quines, L. K., Melo, A. A,Brandellero, M., Mendes, C. R., Schmidell, W., Aragão, G. M. F., High cell density strategy for poly(3hydroxybutyrate) production by Cupriavidus necator. Brazilian Journal of Chemical Engineering, 28, 585-596 (2011).

Karr, D. B., Waters, J. K., Emerich, D. W. Analysis of poly- $\beta$-hydroxybutyrate in Rhizobium japonicum bacteroids by ion-exclusion high-pressure liquid chromatography and UV detection. Applied and Environmental Microbiology, 46, 1339-1344 (1983).

Kourmentza, C., Plácido, J., Venetsaneas, N., Burniol-Figols, A., Varrone, C., Gavala, H. N., Reis, M. A. M., Recent advances and challenges towards sustainable Polyhydroxyalkanoate (PHA) production. Bioengineering, 4, 1-43 (2017).

Lynd, L. R., Overview and evaluation of fuel ethanol from cellulosic biomass: Technology, Economics, the Environment, and Policy. Annual Review of Energy and the Environment, 21, 403-465 (1996).

Madison, L. and Huisman, G., Metabolic engineering of poly(3-hydroxyalkanoates): from DNA to plastic. Microbiology and molecular biology reviews: MMBR, 63, 21-53 (1999).

Martín Santos, M. A., Bocanegra, J. L. F., Martín, A., García, I., Ozonation of vinasse in acid and alkaline media. Journal of Chemical Technology and Biotechnology, 78, No 11), 1121-1127 (2003).

Miller, G. L., Use of dinitrosalicylic acid reagent for determination of reducing sugars. Analytical Chemistry, 31, 426-428 (1959).

Mozumder, Md. S. I.,De Wever, H., Volcke, E. I. P., Garcia-Gonzalez, L., A robust fed-batch feeding strategy independent of the carbon source for optimal polyhydroxybutyrate production. Process Biochemistry, 49, 365-373 (2014).

Myshkina, V. L., Nikolaeva, D. A., Makhina, T. K., Bonartsev, A. P., Bonartseva, G. A. Effect of growth conditions on the molecular weight of poly-3-hydroxybutyrate produced by Azotobacter chroococcum 7B. Prikladnaia biokhimiia i mikrobiologiia, 44, No 5), 533-538 (2008).

Parnaudeau, V., Condom, N., Oliver, R., Cazevieille, P., Recous, S., Vinasse organic matter quality and mineralization potential, as influenced by raw material, fermentation and concentration processes. Bioresource Technology, 99, 1553-1562 (2008).

Posada, J. A., Naranjo, J. M., López, J. A., Higuita, J. C., Cardona, C. A., Design and analysis of poly3-hydroxybutyrate production processes from crude glycerol. Process Biochemistry, 46, 310-317 (2011). 
Pramanik, A., Mitra, A., Arumugam, M., Bhattacharyya, A., Sadhukhan, S., Ray, A., Haldar, S., Mukhopadhyay, U. K., Mukherjee, J., Utilization of vinasse for the production of polyhydroxybutyrate by Haloarcula marismortui. Folia Microbiologica, 57, 71-79 (2012).

Reddy, C. S. K., Ghai, R., Rashmi,Kalia, V. C., Polyhydroxyalkanoates: An overview. Bioresource Technology, 87, No 2, 137-146 (2003).

Salomon, K. R. and Silva Lora, E. E., Estimate of the electric energy generating potential for different sources of biogas in Brazil. Biomass and Bioenergy, 33, 1101-1107 (2009).

Silva, C. F., Arcuri, S. L., Campos, C. R., Vilela, D. M., Alves, J. G. L. F,Schwan, R. F., Using the residue of spirit production and bio-ethanol for protein production by yeasts. Waste Management, 31, 108-114 (2011).

$\mathrm{Yu}$, J. and Stahl, H., Microbial utilization and biopolyester synthesis of bagasse hydrolysates. Bioresource Technology, 99, 8042-8048 (2008). 
